\title{
Survival and movement of the Congo forest mouse (Deomys ferrugineus): a comparison of primary rainforest and fallow land in Kisangani, Democratic Republic of Congo ${ }^{\dagger}$
}

\author{
Jan Kennis ${ }^{1 *}$, Crespin Laurent ${ }^{2,3}$, Nicaise Drazo Amundala ${ }^{4}$, \\ Akaibe Migimiru Dudu ${ }^{4}$ \& Herwig Leirs ${ }^{1,5}$ \\ ${ }^{1}$ Evolutionary Ecology Group, University of Antwerp, Groenenborgerlaan 171, B-2020 Antwerp, Belgium \\ ${ }^{2}$ INRA, UR346 d'Epidémiologie animale, F-63122, Saint-Genès Champanelle, France \\ ${ }^{3}$ Université de Lyon, F-69000, Lyon; Université Lyon 1; CNRS, UMR5558, Laboratoire de Biométrie et Biologie \\ Evolutive, F-69622, Villeurbanne, France \\ ${ }^{4}$ Animal Ecology and Resource Management Laboratory (LEGERA), University of Kisangani, B.P. 2012, \\ Kisangani, Democratic Republic of Congo \\ ${ }^{5}$ Department of Integrated Pest Management, Faculty of Agricultural Sciences, University of Aarhus, \\ Forsøgsvej 1, DK-4200 Slagelse, Denmark
}

Received 1 May 2011. Accepted 24 May 2012

The Congo forest mouse, Deomys ferrugineus, occurs readily in natural and human-altered habitats in the region of Kisangani (Democratic Republic of Congo). We studied survival and movement patterns of $D$. ferrugineus in both habitats. Capture-mark-recapture was used to study the effects of habitat on rodent life history both in primary rainforest and fallow land. Survival analyses taking into account trap-happiness effects were conducted using the program MARK. Abundance of $D$. ferrugineus was generally low within all our study grids, but it was lowest in fallow land compared to primary rainforest. Numbers of reproductively active females captured were not different between habitats but were larger during the rainy seasons. Daily movements of females, but not of males, were smaller in fallow land. Capture-markrecapture analyses showed recapture probabilities to vary highly between grids and years. Survival probability in the primary forest was higher than in fallow land with a difference of 0.084 over a period of four weeks. This is possibly linked to the higher abundance of the main food source (insects and termites); however, other explanations are discussed in the text.

Key words: abundance, capture-mark-recapture, survival analysis, MARK, Deomys ferrugineus.

\section{INTRODUCTION}

Small-scale farming practices are one of the most important factors causing deforestation in Central Africa (Debroux et al. 2007). Itinerant slash-andburn agriculture is widespread in the Democratic Republic of Congo (hereafter DRC, Amundala et al. 2008) and abandoned fields remain fallow for at least six years. This process creates extensive fallow land-agriculture mosaics around the larger centres located in the rainforest, as is the case in the studied region around the city of Kisangani (Amundala et al. 2008).

Some small mammal species occur readily both in the main natural habitat present (primary rainforest) and in the fallow land mosaics (Wilkie

${ }^{\dagger}$ Paper presented at the 4th International Conference on Rodent Biology and Management (ICRBM), 12-16 April 2010, Bloemfontein, South Africa.

*Author for correspondence. E-mail: jan.kennis@ua.ac.be
1990). Several rodent species in the Kisangani region are known to occur both in primary rainforest and fallow land (e.g. Deomys ferrugineus, Praomys cf. jacksoni, Lophuromys flavopunctatus, L. dudui, Hylomyscus stella) but other rodent species such as Dendromys mysticalus and several shrew species seem to prefer primary rainforest, while Stochomys longicaudatus and Oenomys hypoxanthus prefer fallow land (Dudu 1991; Mukinzi et al. 2005). More commensal species habituated to human-altered habitats, such as Rattus rattus, Mastomys natalensis and Mus spp., are invading the fallow-field mosaics (Amundala et al. 2008).

One of the rodent species present in both natural (primary rainforest) and fallow land in the Kisangani region, is the Congo forest mouse Deomys ferrugineus Thomas, 1888 from the monospecific genus Deomys (formerly called the link 
rat). This species only occurs on the right bank of the Congo River (Musser \& Carleton 2005), from Lake Victoria to Cameroon. Its distribution throughout Africa is scattered and populations are present in low densities in Gabon (Duplantier 1989) and in the Ituri Forest in the DRC (Gubista 1999; Katuala et al. 2005) and in high densities in the Kisangani region (Dudu 1991; Amundala et al. 2005; Katuala et al. 2008). The species occurs in all habitats except fields and is classified as a 'forest non-dependent species' (not restricted to closed canopy and occurring in forest edge, gallery forests and dense savanna woodland) in Bwindi Impenetrable National Park, Uganda (Kasangaki et al. 2003).

Deomys ferrugineus is highly distinctive because of its long legs, exceptionally large ears, long tail and bright white belly (Kingdon 1974). It is mostly active at dusk and dawn, occasionally also during the ' and the late afternoon (Kingdon 1974). Individuals are relatively large, between 120 and $140 \mathrm{~mm}$ head-body length and 40 and 70 grams (Dudu 1991). In this study, we focus on life history as a factor determining the adaptability of $D$. ferrugineus to human-induced habitat changes. According to Swihart et al. (2003) several factors may play a role in the adaptability of vertebrates to habitat loss and fragmentation and the major ones are: (1) body size: larger species are more capable of passing through human-altered habitats such as crop fields; (2) morphology and ontogeny, which may impose constraints on habitat use or mobility (e.g. locomotion, life stages in need of multiple habitat types, substrate requirements); (3) social and territorial behaviour: sociality may impose limits on colonization rates and territorial species are more likely to be affected by habitat fragmentation; (4) geographic range boundaries: abundance tends to decline spatially from the core to the periphery of a species' distribution range. Therefore, the effects of fragmentation could be more severe at localities near the edge of a species geographical range; (5) niche breadth: widespread or generalist species should have broader tolerances for environmental changes than individuals of less widespread species.

Little is known about the territorial and social behaviour of $D$. ferrugineus but territoriality has never been documented and crude estimates of home ranges reported are typically large, with females covering $1500-3100 \mathrm{~m}^{2}$ and males 3100$7600 \mathrm{~m}^{2}$ in Gabon (Duplantier 1989). Home ranges are inversely related to the density, however, and densities in Gabon are very low (Duplantier 1989). Most fields in the region are situated within fallow land-field mosaic and are smaller than 1 hectare (Amundala et al. 2008). We therefore predict that D. ferrugineus is able to readily cross smaller human-influenced habitats. The geographic range boundaries of $D$. ferrugineus are situated far from the Kisangani region and therefore the effect of geographic range boundaries should be minimal. Both the effects of body size and ontology are not studied here as we focus on the effects of habitat change one the life history of $D$. ferrugineus.

Life history data are an important measure; reproduction and survival ultimately mark a species' ability to survive in a specific habitat, whatever the underlying factors may be (food availability, cover and nesting availability, predation). Deomys ferrugineus reproduction occurs year-round in the DRC (Rahm 1970; Dieterlen 1986; Dudu 1991); however, Duplantier (1984) and Katuala et al. (2005) reported a correlation between gestation and the rainy seasons with a peak in reproduction during the rains. Population structure is stable and breeding occurs year-round (Katuala et al. 2005) but seems somewhat higher during the rainy season.

Deomys ferrugineus is mainly insectivorous, and specifically a termite specialist (Gembu et al. 1998; O'Brien 2009). Apart from termites, the diet consists of other insects like grasshoppers and crickets; besides millipedes, earthworms and snails (Gembu et al. 1998). Occasionally, they eat vegetable matter, mostly pulp from fallen palm nuts (Elaeis guineensis) and litter (Gembu et al. 1998). Habitat certainly influences abundance and diversity of insects (overview in Watt et al. 1997). Several authors have noted that $D$. ferrugineus is more abundant in closed habitats with undergrowth and fallen logs (Duplantier 1989; Malcolm \& Ray 2000; O'Brien 2009) and suggested that this is due to the high abundance of their main food source, termites. Deomys ferrugineus is less abundant in fallow land than in secondary rainforest and within the edge zone between both habitats, abundance is intermediate (L. Iyongo, unpubl. data). Hence, we hypothesize that survival is better and abundance higher in primary rainforest compared to fallow land.

\section{MATERIALS \& METHODS}

\section{Study area}

We trapped rodents at two sites located in the DRC: 1) Masako (15 km north of the city of 


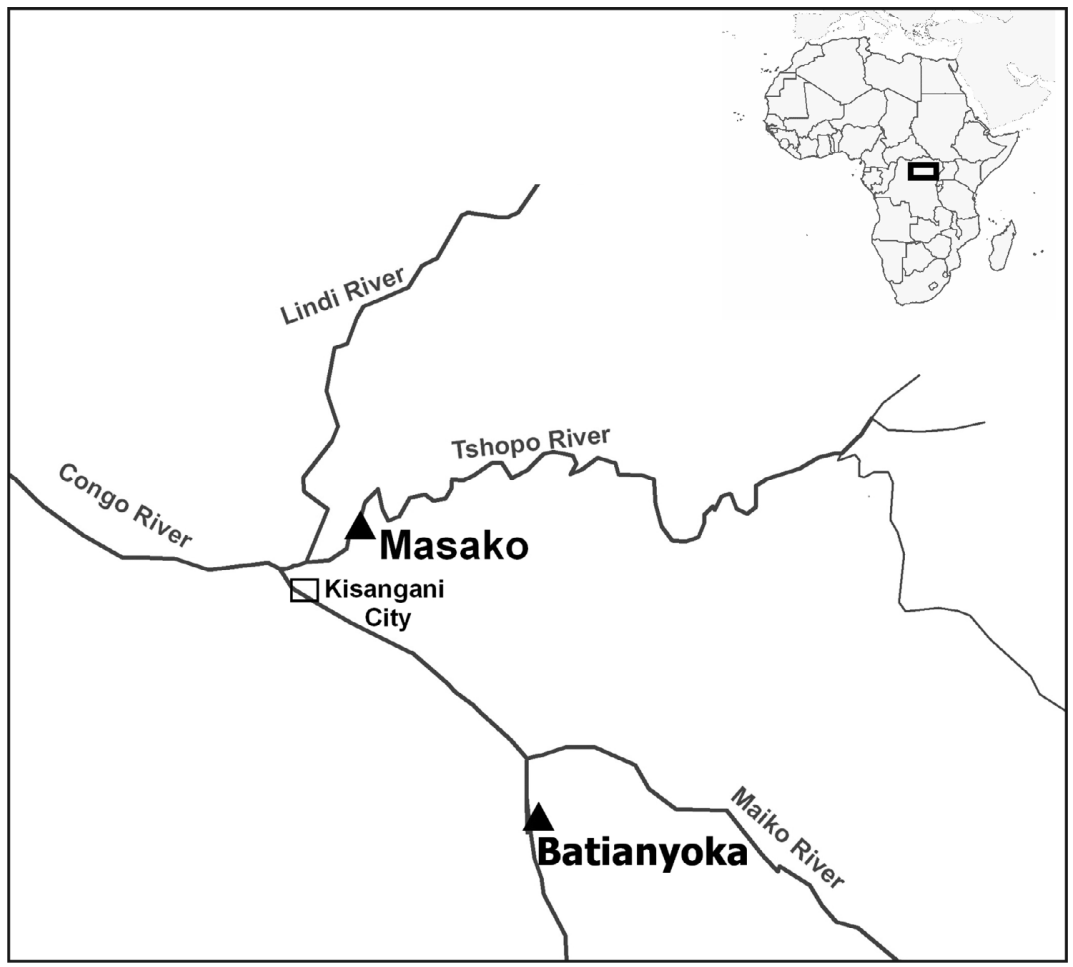

Fig. 1. Map of the Kisangani region showing both study sites (triangles). The limits of the city of Kisangani are indicated with a rectangle. The inset shows the position of the Kisangani region within Africa and the DRC.

Kisangani, GPS coordinates $00^{\circ} 36^{\prime} \mathrm{N}, 25^{\circ} 15^{\prime} \mathrm{E}$ ), and 2) Batianyoka ( $80 \mathrm{~km}$ east of the city of Kisangani, GPS coordinates $00^{\circ} 05^{\prime} \mathrm{N}, 25^{\circ} 33^{\prime} \mathrm{E}$ ) (Fig. 1). The sites were selected because of (1) the proximity between fallow land and remnant primary forests; (2) their comparable sizes (between 10 and $15 \mathrm{~km}^{2}$ ); and (3) the fact that sites are well protected inside the Masako Forest Reserve (recognized by the government and protected by law) and a privately owned forest reserve. In theory all human activities are forbidden in both reserves, but in practice hunting and wood gathering occurs on a regular basis and illegal charcoal production sometimes causes gaps in the forest cover. The sites were also chosen because of the distance between them (approximately $100 \mathrm{~km}$ ) and the big Maiko River situated between the populations, thus allowing us to consider these populations as non-connected and independent sites. The fallow habitat consists of abandoned agricultural fields left fallow for between four and six years. Both primary forest plots consist of mixed primary rainforest with more open undergrowth compared to fallow land. A tropical climate is present at both sites situated close to the equator. The climate is characterized by the absence of real dry seasons and the presence of rains year-round. We obtain monthly rainfall means (in mm per month rainfall) and monthly temperature means taken during daytime $\left({ }^{\circ} \mathrm{C}\right)$ for the period 2005-2008 from the meteorological station at Bangboka International Airport, Kisangani (source: MONUC, United Nations). Figure 2 shows the average rainfall and temperature over the four years of available data. Daily temperatures remain between $27^{\circ} \mathrm{C}$ and $31^{\circ} \mathrm{C}$ year-round. Two drier periods are observed in December-February and June/July.

Rodents were captured during a two-year capture-mark-recapture (hereafter CMR) study from March 2007 to May 2009. Trapping occurred simultaneously in both fallow land and primary rainforest at each trapping locality. A total of $27 \mathrm{CMR}$ sessions were organized with a constant interval of four weeks. The CMR sessions at Batianyoka were organized two weeks after Masako CMR sessions, a time-shift maintained throughout the study. Rodent composition was similar at both sites and the most common rodent species within three studied genera (Katuala et al. 2008) were Praomys cf. jacksoni, Lophuromys dudui 


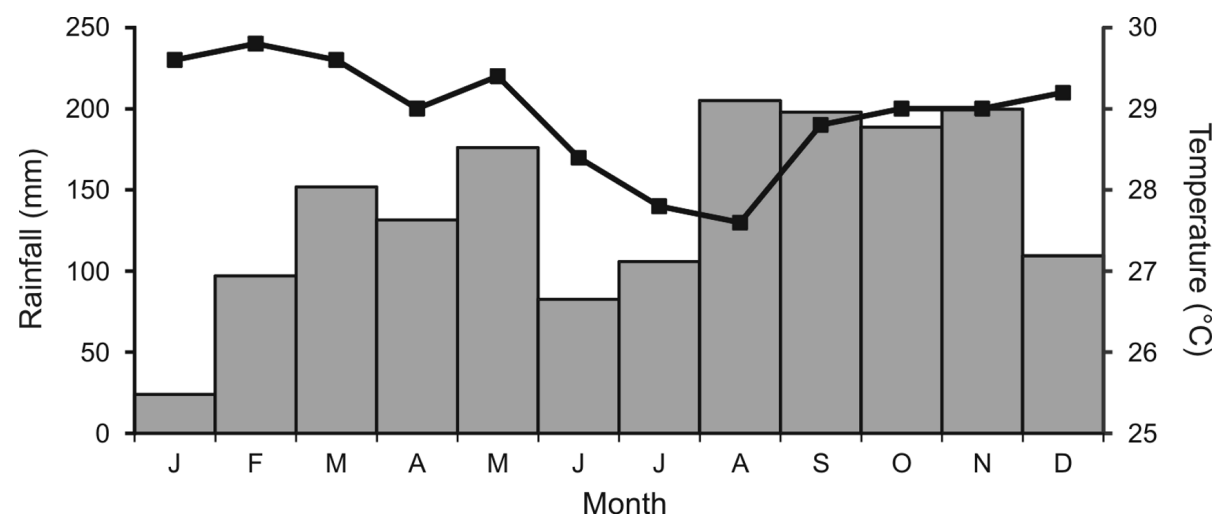

Fig. 2. The climate of Kisangani: mean monthly temperature (black line, right $y$-axis) and mean monthly rainfall (grey bars, left $y$-axis) based on data from 2005 to 2008 (Bangboka International Airport, Kisangani; source: MONUC).

and Deomys ferrugineus. Hylomyscus stella was also common in Masako but unstudied in Batianyoka (Dudu 1991). D. ferrugineus is easily distinguishable, however, from all other rodent species captured during our CMR study owing to its particular morphology. Both at Masako and Batianyoka, primary rainforest and fallow land habitats were sampled using a $100 \times 100 \mathrm{~m}$ grid (100 traps; Sherman HB Inc, Tallahassee, U.S.A.) for five consecutive's. The distance between the fallow land grid and the primary rainforest grid was $2 \mathrm{~km}$ at each site. Traps were baited daily with palm nut pulp, commonly used in the region with good results (Dudu 1991; Mukinzi et al. 2005; Katuala et al. 2008). Traps were set up just before dusk and left open during the following night and day. Traps were checked every morning between 6 and 8 a.m. Captured animals were transported within the traps to a field laboratory. We examined and measured captured animals to determine species, sex, age, reproductive status and mass (g). Captured individuals were uniquely marked on first capture using toe clipping, a permanent marking method. Each individual was subsequently released at the exact spot of capture within the grid. Traps containing shrews were replaced because their lingering odour repels rodents. Three $D$. ferrugineus individuals died at release (two in the Batianyoka fallow: one pregnant female and one subadult male; one in the Masako fallow: an adult male). Two individuals died in the trap before collecting in the Masako primary rainforest (a subadult female and an adult male). The frequency of accidental deaths was thus low and these individuals were indicated as not released for further analyses.

\section{Data analyses}

Abundance and reproduction. Because of the lack of recaptures during the primary trapping sessions (PTSs), all attempts to use closed-population models (Otis et al. 1978) failed and statistical models based on open-population models could not be used because of the lack of data, the high degree of heterogeneity and observed trap happiness. Population size was thus estimated using direct enumeration, comparing the number of captured individuals within PTSs with the Minimum Numbers Known Alive (MNKA) (Krebs 1966). Both counts were compared because MNKA is known to show some tapering bias, which is more pronounced in the middle of the study and when survival rates between PTSs are high (Pocock et al. 2004). Comparing the trends seen in MNKA and direct enumeration could give us some information about the catchability, for instance when there is a large difference between the MNKA and short high (or low) peaks in numbers using direct enumeration. During these periods, abundance could be stable (as shown by MNKA) but trap shyness or happiness could occur.

We counted the number of reproductively active female individuals captured (pregnant and/or lactating) per season and per habitat. A chi-square test was used to test whether season or habitat influenced the observed numbers. All rainy seasons and all drier seasons within the dataset were pooled because of the lack of data.

Movements and number of transients. To study the impact of habitat on daily movements, Euclidean distances between captures (occurring within PTSs) were computed for individuals captured at least twice within a PTS (Leirs et al. 1996; Kennis 
et al. 2008). The median and maximum distances covered between capture occasions were subsequently calculated per individual over all PTSs to study both types of distances covered. A G-test was used to compare the calculated median movements to all possible movements in the $100 \times$ $100 \mathrm{~m}$ grid. Mann-Whitney $U$-tests were used to compare the differences in median movements between females and males and between both habitats (pooled over both localities). Because only four subadult animals were recaptured within the PTSs, only adults were used for distance calculations. The number of transients was calculated as the number of animals caught only once over the two-year period.

Survival analyses. The analysis of CMR data was carried out following Lebreton et al. (1992) and allows the estimation of two parameters: a demographic parameter, the probability of survival (calculated over four weeks), denoted S, and a nuisance parameter, the probability of recapture, denoted P. Thus we start by assessing the goodness of fit of a general model to the data and then, from this general model, carried out a model selection from a set of candidate models.

Goodness-of-fit tests. The goodness of fit of the general model to the data was assessed by running four tests: 3SR, 3SM, 2CT and 2CL (Pradel et al. 2005) using the software UCARE 2.3.2 (Choquet et al. 2009). These four tests test for the goodness-of-fit to the general Cormack-Jolly-Seber model. In particular, the presence of transients (3SR and 3SM) and trap-dependence (2CT and 2CL) are tested (Pradel et al. 2005). Owing to the paucity of data, GOF tests from the data split by age class and grid did not yield sensible interpretations. Given that our main question was the difference in survival between habitats, we thus pooled the data over both localities per habitat.

Model selection. As recommended by Anderson et al. (1998), model selection was performed with the Akaike's information criterion corrected for small sample sizes (hereafter $\mathrm{AIC}_{\mathrm{c}}$ ). The smaller the criterion, the better the model in comparison between nested models. For each model, we calculate the difference in $\mathrm{AIC}_{\mathrm{c}}$ (presented as $\Delta \mathrm{AIC}_{\mathrm{c}}$ ) from the model with the lowest $\mathrm{AIC}_{\mathrm{c}}$ score and the Akaike weight of the model that can be interpreted as a relative degree of support for a given model within the set of candidate models (Link \& Barker 2006). Anderson et al. (1998) suggested the following rules of thumb for model selection: all models with $\Delta \mathrm{AIC}_{\mathrm{c}} \geq 10$ are essentially not supported by the data and can be safely ignored, all models with a $\triangle \mathrm{AIC}_{\mathrm{c}}$ in the range 3-7 are relatively supported by the data and should be taken into account, and all models with $\Delta \mathrm{AIC}_{\mathrm{c}}<2$ are strongly supported by the data and should be used when making inferences about the demographic parameters. Further we expected that several models would come close in terms of $\mathrm{AIC}_{\mathrm{c}}$ because of the paucity of data and that it would be difficult to single out a best model to make inferences about the demographic parameters. An alternative is to use the Akaike weights to yield weighted estimates of the demographic parameters averaged over all models in the set of models (Burnham \& Anderson 2004). A major advantage of these weighted estimates is that they allow taking into account explicitly the uncertainty in the model selection beyond the sampling variation of each model.

Set of candidate models for the survival analysis. Even though the four grids were sampled every four weeks over two years, the data were sparse because the abundance of $D$. ferrugineus was generally low for the duration of the study. Thus, we attempted to keep the number of parameters low in all models and consider only a few biologically relevant variables. First, data were split according to categories related to functional age class, based on maturation. For males, we considered as subadults all individuals with abdominal testicles (scrotal testicles for the adults). For females, adults were characterized by a perforated vagina, clear signs of pregnancy (swollen abdomen, at least two weeks pregnant) or swollen, lactating teats. Transitions from adult to subadult were removed prior to the analyses. The number of individuals caught both as subadult and as adult, however, was very low, which impelled us to model the maturation from subadult to adult. Thus, the capture histories of these 22 individuals were split according to Julliard et al. (1999) and age class was subsequently used as a factor in all CMR analyses. Preliminary analyses revealed that there were no differences in survival estimates between males and females, thus the gender factor was dropped from the analysis. Earlier works reported that breeding occurs year-round in D. ferrugineus (Rahm 1970; Dudu 1991). Differences between the seasons in number of offspring were absent but yearly differences in number of offspring were presented (Dudu 1991). Therefore we did not consider seasonal variation but only year-to-year variation (variable year with two levels). Ideally we should have included in the 
Table 1. Primary trapping data split up per locality and habitat: average number of recaptures per individual (ANC), average number of individuals per month (ANI), number of captures and recaptures in brackets for subadult males (SUBM), adult males (ADM), subadult females (SUBF) and adult females (ADF). Also indicated are the number of transitions from subadult to adult (TSA) and the percentage of subadult and adult transients (TRS and TRA).

\begin{tabular}{|c|c|c|c|c|c|c|c|c|c|c|}
\hline Habitat & Grid & ANC & ANI & SUBM & ADM & SUBF & ADF & TSA & TRS & TRA \\
\hline \multirow[t]{2}{*}{ Primary forest } & Batianyoka & 1.60 & 2.96 & $1(2)$ & $23(20)$ & $11(6)$ & $11(14)$ & 4 & 66.7 & 44.1 \\
\hline & Masako & 3.69 & 8.17 & $2(0)$ & 59 (129) & $12(16)$ & $32(62)$ & 12 & 56.6 & 35.2 \\
\hline \multirow[t]{2}{*}{ Fallow land } & Batianyoka & 1.69 & 3.57 & $2(2)$ & $26(60)$ & $16(20)$ & $12(34)$ & 4 & 70.0 & 79.4 \\
\hline & Masako & 2.26 & 1.76 & $1(0)$ & $20(8)$ & $9(5)$ & $14(6)$ & 2 & 78.8 & 50.0 \\
\hline
\end{tabular}

analysis a random effect for grid and a fixed effect for habitat. However, Burnham \& White (2002) advised not to use random effects with less than 10 levels on the basis of simulations of the full-time dependent model. Therefore we used models with grid and habitat as fixed effects in the model selection. We also ran additive models when these represented a large decrease in the number of parameters compared to models with the same variables and interactions. To sum up, 48 candidate models were run. All the models were fitted in MARK 5.1 (White \& Burnham 1999).

\section{RESULTS}

\section{Abundance and reproduction}

Our study totalled 57000 trapping days and nights over the four grids. More individuals were captured in primary forest $(n=151)$ compared to fallow land $(n=100)$ as shown in Table 1. More recaptures were also noted in primary forest $(n=249)$ compared to fallow land $(n=135)$. More individuals were captured in Masako primary forest $(n=105)$ compared to Batianyoka primary forest $(n=46)$. A similar number of individuals were captured in both fallow land grids $(n=44$ at Masako and $n=56$ at Batianyoka). Very few male subadults were (re)captured during our study (six individuals and four recaptures) compared to male adults (128 individuals and 217 irecaptures). Slightly more males $(n=85)$ were captured in primary forest compared to females $(n=66)$ but the numbers were equal for males $(n=49)$ and females $(n=51)$ in fallow land. The abundance was generally low (Fig. 3). MNKA and the number of captures were often concordant at both sites (but less so during some PTSs in primary forest). From the MNKA estimates, it was clear, however, that during two PTSs without captures, once in the fallow land and once in the primary rainforest of Batianyoka, at least one individual remained in the population. This contrasted with the fallow land at Masako, where six sessions lacked any captures. Some variation in abundance between years within the grids was apparent and a clear difference could be seen between both localities: in Batianyoka abundance was generally low in both habitats, whereas in Masako the abundance in the fallow land was lower than in the primary forest. A clear rise in abundance was only noticeable in Masako for both habitats during January/February 2008 and only in primary rainforest during the period December 2008 - February 2009. This may have reflected an increase in catchability rather than an increased abundance given that both MNKAs and the number of captured individuals were not corrected for variation in catchability.

The number of pregnant and/or lactating females per habitat and per season is shown in Fig. 4. Numbers of reproductive females captured were the same between habitats $\chi^{2}=0.30$, d.f. $=1$, $P=0.58)$. By contrast, numbers of reproductive females were different between seasons (when combining habitats): less than expected reproductively active females were captured during the drier season and more during the rainy season $\left(\chi^{2}=6.42\right.$, d.f. $\left.=1, P=0.011\right)$.

\section{Movements and number of transients}

The calculated percentage of transients was high both for subadults and adults (Table 1). Subadults showed a similar number of transients in both habitats $\left(\chi^{2}=1.38, P=0.29\right.$, d.f. $=3$ ); but adults showed a significantly higher number of transients in the fallow land $\chi^{2}=0.0052, P=0.0001$, d.f. $=3$ ). The $G$-test for the difference between noted median movements and all possible movements in the grid was highly significant $(G=80.62$, d.f. $=14, P=2.17^{-11}$ ), indicating the distribution of male and female movements did not follow the distribution of all possible movements within the grid. The distribution of median distances covered 

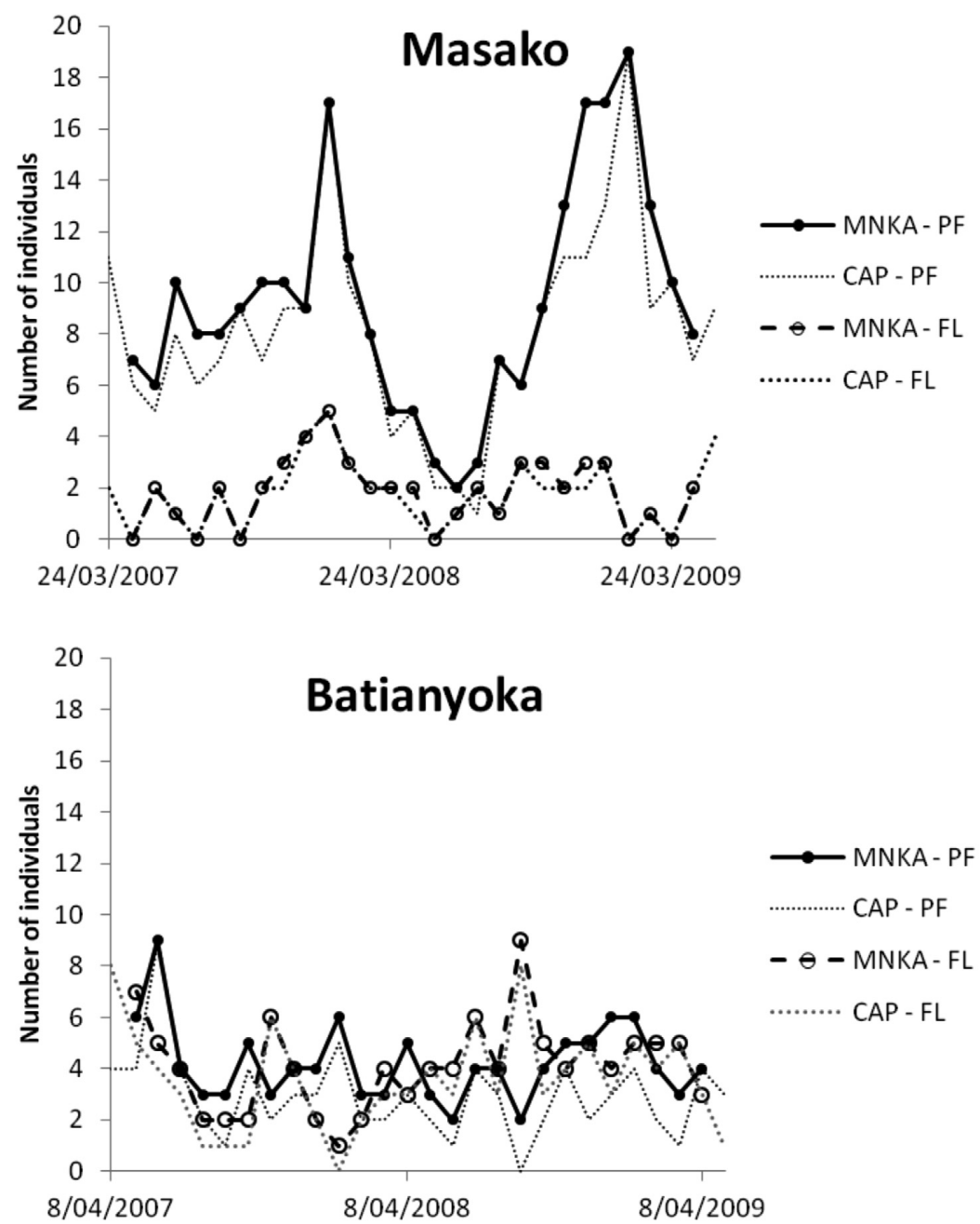

Fig. 3. Total number of individuals per month for each grid. MNKA represents the minimum number known alive estimates, CAP represents the number of individuals captured during a PTS. PF represents the primary forest and FL represents the fallow land.

by individuals in both habitats is shown in Fig. 5 . Within the fallow land, female median movements were significant smaller than male median movements (males: $24.4 \mathrm{~m}$; females: $9.7 \mathrm{~m}$; $\mathrm{Z}=-2.834$, $n=14, P=0.003$ ) but there was no difference in the primary rainforest (males: $37.0 \mathrm{~m}$; females: $30.0 \mathrm{~m} ; Z=-1.443, n=54, P=0.15)$. The maximum distance covered in the primary rainforest by adult males was $89.4 \mathrm{~m}$ and by adult females $86.0 \mathrm{~m}$, both at Masako. The maximum distance covered in the fallow land was $46.4 \mathrm{~m}$ by males (Masako) and only $16.7 \mathrm{~m}$ by females (Batianyoka). There was a significant difference in the median distances covered per habitat when pooling males (median distance covered) and females together
$(Z=-3.233, n=68, P=0.001)$. The habitat difference, however, was not significant in males $(Z=-1.634, n=42, P=0.107)$ but it was significant in females $(Z=-3.234, n=26, P<0.001)$. Sample sizes were small in the fallow land (eight male movements, six female movements) compared to primary rainforest ( 34 male movements, 20 female movements). No marked individuals from the grids in fallow land were captured in primary rainforest and vice versa.

\section{Goodness-of-fit tests}

Although GOF tests indicated a marginal lack of fit due to trap happiness $(Z=-1.9344, P=0.053)$, overall the model fitted the data $\chi^{2}=35.496$, 


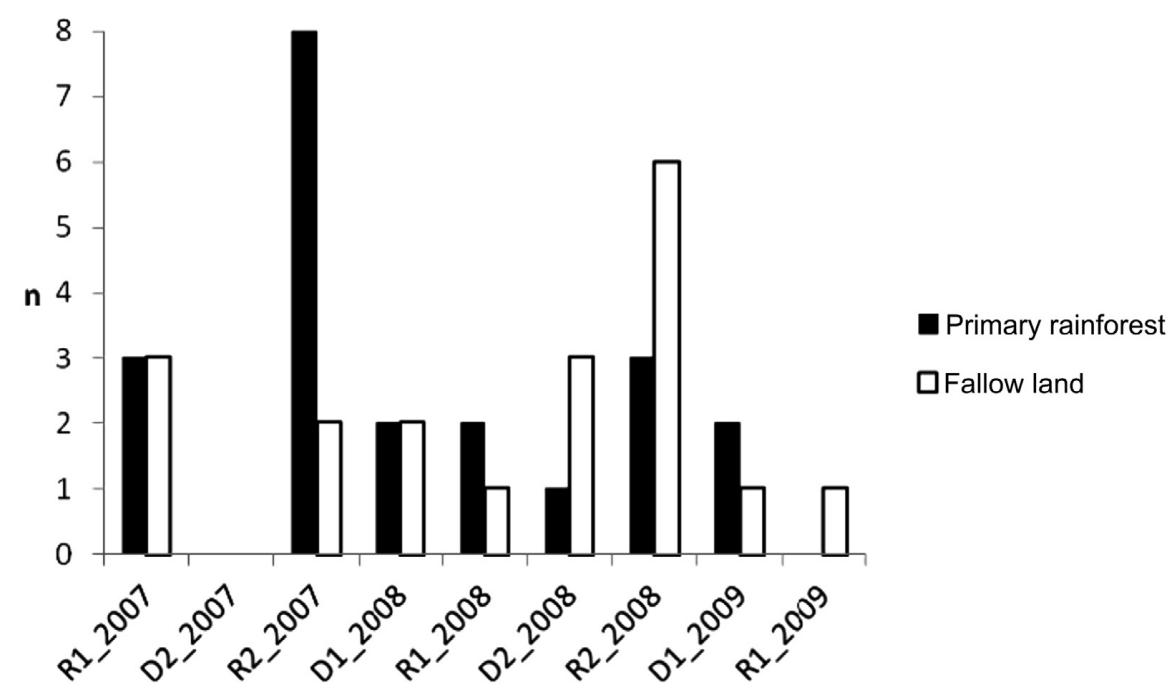

Fig. 4. Number of lactating and/or pregnant females in primary rainforest and fallow land (both localities combined) during the different seasons and years. Filled bars represent primary rainforest, open bars represent fallow land. $R$ indicates the rainy season and $D$ indicates the drier season. The numbers represent the first and second season within the year.

d.f. $=105, P=1)$. Nevertheless, we included in the modelling two probabilities of recapture to take into account trap happiness (Gimenez et al. 2003): $P^{\prime}$ (the probability of recapture, given that the animal was not caught during the previous occasion) and $\mathrm{P}^{\prime \prime}$ (the probability of recapture, given that the animal was caught during the previous occasion). The difference between a model with and without trap happiness was in fact strongly significant $($ LRT $=8.744$, d.f. $=1, P=0.0031$ between Model $\mathrm{S}_{(.)} \mathrm{P}_{(.)}^{\prime \prime} \mathrm{P}_{(.)}^{\prime}$ and Model $\left.\mathrm{S}_{(.)} \mathrm{P}_{(.)}\right)$, indicating the inclusion of trap happiness in the recapture probability improved significantly the fit of the models for D. ferrugineus.

\section{Model selection}

\section{Probability of recapture}

After preliminary analyses, the interactions age $x$ year, age $\times$ habitat and habitat $\times$ year in the probability of recapture were discarded because these interactions did not improve the fit of models when included in recapture probabilities.

Of the final model set, all first 15 models but one $\left(\mathrm{S}_{\text {(year) }} \mathrm{P}^{\prime \prime}\right.$ (grid $\times$ year) $\mathrm{P}^{\prime}$ (grid $\times$ year) $\mathrm{AIC}_{\mathrm{c}}=921.43$ $\left.\Delta \mathrm{AIC}_{\mathrm{c}}=3.57\right)$ included the variables grid and year either with or without an interaction (Table 2). The first three models in terms of AIC $_{c}$ were all additive models. The model with the lowest $\mathrm{AIC}_{\mathrm{c}}$, including the interaction between grid and year, was ranked fourth $\left(\left(\mathrm{S}_{(.)} \mathrm{P}^{\prime \prime}{ }_{\text {(grid }} \times\right.\right.$ year) $\mathrm{P}^{\prime}$ (grid $\times$ year) $\mathrm{AIC}_{\mathrm{c}}=$
919.77 $\left.\Delta \mathrm{AIC}_{\mathrm{c}}=1.91\right)$. Evidence for the inclusion of the interaction was marginal $\left(\chi^{2}=10.95\right.$, d.f. $=6$, $P=0.09$ compared to the minimum AIC $_{\mathrm{c}}$ model) and therefore we presented unweighted estimates of recapture probabilities from the model without

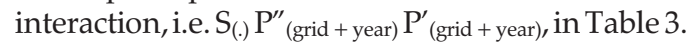

\section{Probability of survival}

The modelling of survival demonstrated clear data paucity as (i) the model with minimum $\mathrm{AIC}_{\mathrm{C}}$ score displayed no variation in survival (model $S_{(.)}$ $\mathrm{P}^{\prime \prime}{ }_{\text {(grid }+ \text { year) }} \mathrm{P}_{\text {(grid + year) }} \mathrm{AIC}_{\mathrm{c}}=917.86, \mathrm{np}=11$, see Table 2) and (ii) five models with a similar number of parameters were included within about two units of $\mathrm{AIC}_{\mathrm{c}}$ from the model with minimum $\mathrm{AIC}_{\mathrm{c}}$ score. Among these five models, the first two models reached almost exactly the same $\mathrm{AIC}_{c}$ $\left(\Delta \mathrm{AIC}_{\mathrm{c}}=0.01\right)$. The inclusion of the variable 'habitat' relative to the model with no variation in survival was not significant $\chi^{2}=2.11$, d.f. $=1, P=$ 0.15 ) and thus cannot be fully supported based on our data. The estimate of survival (with the lower and upper 95\% confidence intervals indicated between brackets) for primary forest was 0.696 (0.638-0.748) while the estimate for fallow land was $0.612(0.512-0.704)$ from the model $S_{\text {(habitat) }}$ $\mathrm{P}^{\prime \prime}{ }_{\text {(grid }+ \text { year) }} \mathrm{P}^{\prime}$ (grid + year), resulting in a difference in the four-week survival rate between habitats of 0.084 . The variable 'year' was less supported by the data (Model $\mathrm{S}_{\text {(year) }} \mathrm{P}^{\prime \prime}$ (grid + year) $\mathrm{P}^{\prime}$ (grid + year) $\left.\Delta \mathrm{AIC}_{\mathrm{c}}=1.54\right)$. From model $\mathrm{S}_{(\text {year })} \mathrm{P}^{\prime \prime}$ (grid + year) $\mathrm{P}^{\prime}$ (grid + 

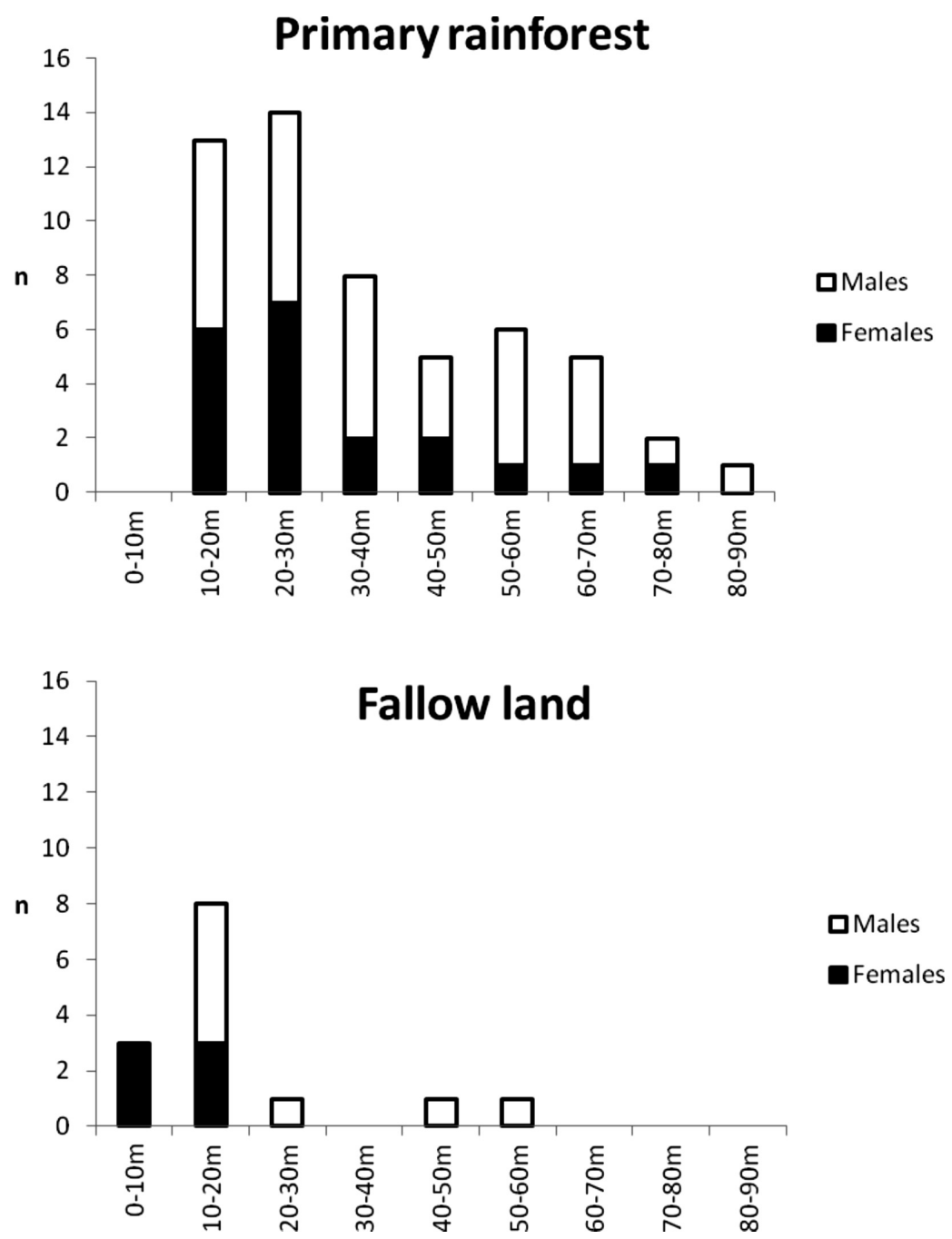

Fig. 5. Number of individuals with their mean distances covered between captures in both habitats by males and females.

year), survival was estimated, respectively, in the first and the second year as $0.65(0.57-0.73)$ and 0.69 (0.62-0.76). Support for the variable age class was weak (model $\mathrm{S}_{\text {(age) }} \mathrm{P}^{\prime \prime}$ (grid + year) $\mathrm{P}^{\prime}$ (grid + year) $\Delta \mathrm{AIC}_{\mathrm{c}}=$ 2.05). The survival estimate for adults is 0.68 (0.62-0.73) and for subadults 0.67 (0.62-0.73) from

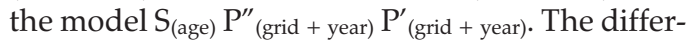
ence between adult and subadult survival estimates was small (0.01) and thus biologically irrelevant.

Given that the paucity of data impelled us to single out one best model, we presented modelaveraged estimates of survival over the whole set of models (see Table 4). As seen in the large 95\% confidence intervals of these estimates, the uncer- tainty due to model selection was rather large (between 26 and $53 \%$ of the variance).

\section{DISCUSSION}

Deomys ferrugineus abundance was low in both habitats. Abundance was lower in the Masako fallow land than in primary rainforest but similar in both habitats in Batianyoka. Females covered shorter distances in fallow land, while males covered similar distances in both habitats. Habitat was included as a factor influencing survival in the second best model but support for this model was not distinguishable from the model with a constant survival rate throughout the study period, likely due to the low number of recaptures. 
Table 2. Model selection in MARK: 15 best ranked models $\left(\triangle \mathrm{AIC}_{\mathrm{c}}<7\right)$.

\begin{tabular}{|c|c|c|c|c|}
\hline Model & $\mathrm{K}$ & Dev. & $\mathrm{AIC}_{\mathrm{c}}$ & $\Delta \mathrm{AlC}_{\mathrm{c}}$ \\
\hline $\mathrm{S}(.) \mathrm{P}^{\prime \prime}$ (grid + year) $\mathrm{P}^{\prime}$ (grid + year) & 11 & 895.22 & 917.86 & 0.00 \\
\hline$S\left(\right.$ hab) $P^{\prime \prime}$ (grid + year) $P^{\prime}$ (grid + year) & 12 & 893.11 & 917.87 & 0.01 \\
\hline $\mathrm{S}$ (year) $\mathrm{P}^{\prime \prime}$ (grid + year) $\mathrm{P}^{\prime}$ (grid + year) & 12 & 894.64 & 919.40 & 1.54 \\
\hline $\mathrm{S}(.) \mathrm{P}^{\prime \prime}($ grid $\times$ year $) \mathrm{P}^{\prime}($ grid $\times$ year $)$ & 17 & 884.26 & 919.78 & 1.91 \\
\hline $\mathrm{S}\left(\right.$ age) $\mathrm{P}^{\prime \prime}$ (grid + year) $\mathrm{P}^{\prime}$ (grid + year) & 12 & 895.15 & 919.92 & 2.05 \\
\hline$S\left(\right.$ hab) $P^{\prime \prime}\left(\right.$ grid $\times$ year) $P^{\prime}($ grid $\times$ year $)$ & 18 & 882.37 & 920.07 & 2.20 \\
\hline $\mathrm{S}$ (grid) $\mathrm{P}^{\prime \prime}$ (grid + year) $\mathrm{P}^{\prime}$ (grid + year) & 14 & 891.09 & 920.12 & 2.26 \\
\hline $\mathrm{S}\left(\right.$ hab $\times$ year) $\mathrm{P}^{\prime \prime}\left(\right.$ grid + year) $\mathrm{P}^{\prime}($ grid + year $)$ & 14 & 892.26 & 921.29 & 3.43 \\
\hline $\mathrm{S}_{(\text {year) }} \mathrm{P}^{\prime \prime}$ (grid) $\mathrm{P}^{\prime}$ (grid) & 10 & 900.89 & 921.43 & 3.57 \\
\hline $\mathrm{S}\left(\right.$ year) $\mathrm{P}^{\prime \prime}\left(\right.$ grid $\times$ year) $\mathrm{P}^{\prime}($ grid $\times$ year $)$ & 18 & 883.83 & 921.52 & 3.66 \\
\hline $\mathrm{S}($ age $) \mathrm{P}^{\prime \prime}($ grid $\times$ year $) \mathrm{P}^{\prime}($ grid $\times$ year $)$ & 18 & 884.24 & 921.93 & 4.07 \\
\hline $\mathrm{S}\left(\right.$ age $\times$ hab) $\mathrm{P}^{\prime \prime}$ (grid + year) $\mathrm{P}^{\prime}$ (grid + year $)$ & 14 & 893.06 & 922.09 & 4.23 \\
\hline $\mathrm{S}\left(\right.$ grid) $\mathrm{P}^{\prime \prime}\left(\right.$ grid $\times$ year) $\mathrm{P}^{\prime}($ grid $\times$ year $)$ & 20 & 880.69 & 922.78 & 4.92 \\
\hline $\mathrm{S}\left(\right.$ hab $\times$ year) $\mathrm{P}^{\prime \prime}\left(\right.$ grid $\times$ year) $\mathrm{P}^{\prime}($ grid $\times$ year $)$ & 20 & 881.14 & 923.23 & 5.37 \\
\hline $\mathrm{S}\left(\right.$ age $\times$ year) $\mathrm{P}^{\prime \prime}\left(\right.$ grid + year) $\mathrm{P}^{\prime}($ grid + year $)$ & 14 & 894.48 & 923.51 & 5.65 \\
\hline $\mathrm{S}\left(\right.$ hab $\times$ year) $\mathrm{P}^{\prime \prime}\left(\right.$ grid) $\mathrm{P}^{\prime}$ (grid) & 12 & 899.00 & 923.76 & 5.90 \\
\hline $\mathrm{S}\left(\right.$ age $\times$ hab) $\mathrm{P}^{\prime \prime}\left(\right.$ grid $\times$ year) $\mathrm{P}^{\prime}($ grid $\times$ year $)$ & 20 & 882.35 & 924.44 & 6.58 \\
\hline $\mathrm{S}(.) \mathrm{P}^{\prime \prime}$ (grid) $\mathrm{P}^{\prime}$ (grid) & 9 & 906.41 & 924.84 & 6.98 \\
\hline
\end{tabular}

Only one CMR study known to us had captured $D$. ferrugineus before in a primary rainforest in Gabon (Duplantier 1989). Although Duplantier (1989) used a larger grid of 300 by $300 \mathrm{~m}$, with traps interspaced at $20 \mathrm{~m}$ during 20 consecutive trapping nights, the number of individuals captured per session was comparable to ours (24 to 3 in Gabon compared to 19 to 0 over all our grids). The apparent seasonal rise in abundance we observed twice in the Masako primary rainforest and once in the Masako fallow land was not expected since no clear reproductive periods were found earlier in the Kisangani region (Amundala et al. 2005). These periods of higher abundance occurred just after the rainy seasons, during drier periods (December-February and June/July). Habitats in the Batianyoka and Masako primary rainforests were similar (mixed primary forest) with few to no fallen logs. However, the presence of Uapaca guineensis, a stilt root tree confined to hydromorphic soils (Thoen \& Ba 1989), indicated the mixed primary forest at Masako was probably more humid than Batianyoka. Possibly the seasonal effect at Masako was influenced by a rise in humidity in the forest grid during the rainy seasons, although the forest floor was not inundated during these periods. Deomys ferrugineus diet is almost exclusively composed of arthropods, mainly termites (Gembu et al. 1998). If its abundance was regulated by food availability, it should be less directly dependent on tree composition or fruiting periods compared to fruit-eating rodents such as the Central American spiny rat (Adler 1998), except when tree composition significantly influenced the arthropod community. Happold (1996) noted that there is indeed a decline in insect numbers and species richness in the dry season in Guinea and the Republic of Congo. The factor habitat (fallow land as opposed to primary rainforest) was present in seven of 15 survival models with $\triangle$ AICc. Survival probability in the primary forest was higher than in fallow land. The main D. ferrugineus food source (termites and other insects) was more abundant in primary forests because termite mounds dry out due to forest clearance, causing a significant decline in termite abundance and biomass in the area (Eggleton et al. 2002).

There were almost no male subadults present in all grids, contrary to the work of Amundala et al. (2005). The diagnostic feature used in our study to define adult males (presence of scrotal testes) had frequently been used in other live rodent studies (Leirs 1995; Wells et al. 2004; Makundi et al. 2006). A male-biased sex ratio noted by Dudu (1991) was mainly caused by a surplus of young adult males. Dudu (1991) suggested this could be linked to males moving more to find mates and thus getting caught more often, however, adult males could also be trap-happy because of the odour of oestrus females in the traps (Drickamer 1997). Subadult male rodents are known to disperse (Wolff 2007) and following Dudu (1991) they should therefore 


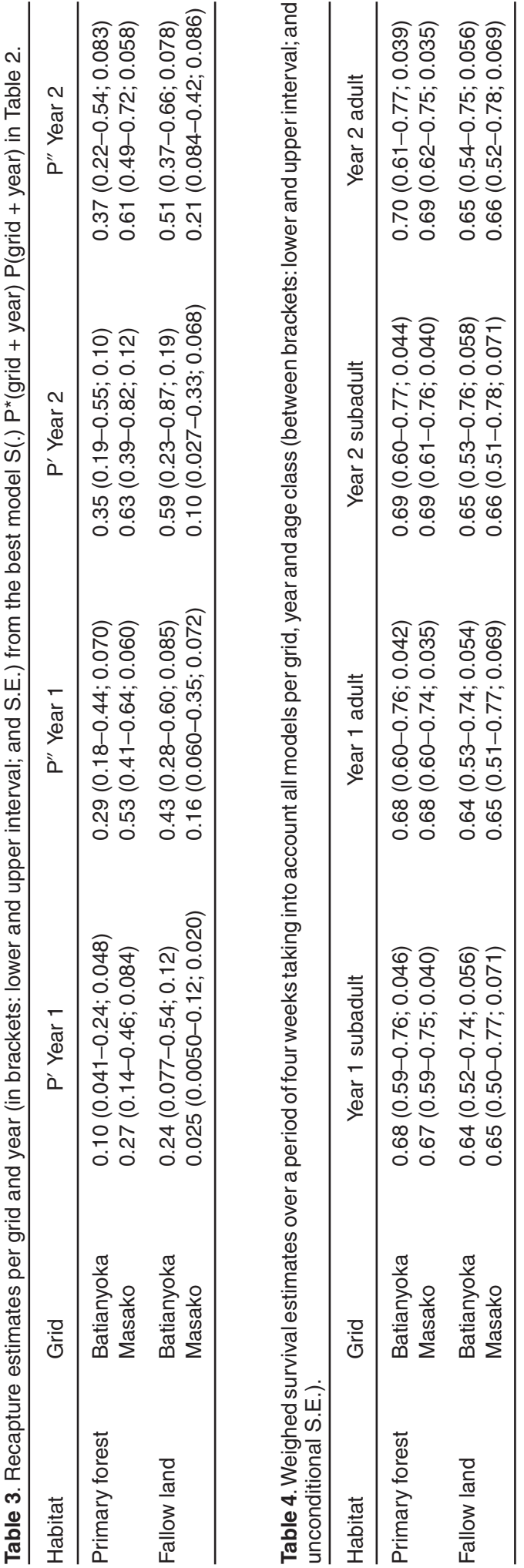

have more chance of being captured in the grids during dispersal. The absence of subadult males in our data, despite the use of proven techniques, could therefore indicate errors in differentiating subadult males from adult males. Female D. ferrugineus covered smaller distances in fallow land compared to primary rainforest. Males covered similar distances in both habitats. Maximum distances covered between two trapping occasions within a PTS were smaller in fallow land compared to primary rainforest. Individuals choose to move within their home range based on many factors such as predator presence (Yunger 2004), availability of food and shelter. A study on movement patterns of the tropical rat Leopoldamys sabanus in Borneo in both unlogged and logged forests showed that paths taken by individual rodents were most likely responses to the local distribution of resources in the heterogeneous rainforest and were not influenced by the largerscale logging process (Wells et al. 2008). The lack of cover in fallow land habitats, the less abundant presence of soil-feeding termites (Eggleton $e t$ al. 2002) and the caring for offspring could all decrease the number of female movements in fallow land. The distribution of daily movements did not follow the distribution of all possible distances within the grid, indicating other factors than grid size influenced daily movements.

Excursion and dispersal activity were more difficult to detect using this setup (Leirs et al. 1996) and therefore it is difficult to discuss the influence of habitat on dispersal patterns based on our CMR data alone. We also detected trap happiness in recaptures which may have partly occurred because grid size was smaller than the home range of D. ferrugineus (Duplantier 1989). This inevitably had an impact on the (re)capture probabilities as illustrated by the high proportion of transients and the strong variation in recapture probabilities between grids and years although climatic conditions were alike in both years and experimental design remained unchanged over the study period.

In conclusion our study detailed the abundance, reproduction and life history of $D$. ferrugineus in both primary rainforest and fallow land. There was significant variation between years and grids in recapture probabilities but a rather small variation between years in survival probabilities. A longer study, using a larger grid, would be necessary to study in more detail the factors modelling survival. To study the mechanisms behind the important 
temporal variation in rodent abundance in this region, all external factors influencing rodent abundance and survival should be studied independently (e.g. predation, fruit and insect availability, nesting availability). A larger area of homogeneous habitat will, however, be difficult to find in our study region, especially with regards to fallow land.

\section{ACKNOWLEDGEMENTS}

We are grateful to our field staff for the sampling effort, especially Edouard Mgongo, Bruno Mondenga, José Akaibe and Michel Komba, Patrick Mutombo and Roger Angoyo. Fieldwork in the DRC was partly funded by the Flemish Inter-University Council, University Development Cooperation (VLIR-UOS). Jan Kennis was supported by a grant as Fellow from the Research FoundationFlanders (Belgium).

\section{REFERENCES}

ADLER, G.H. 1998. Impacts of resource abundance on populations of a tropical forest rodent. Ecology 79: 242-254.

ADLER, G.H. \& BEATTY, R.P. 1997. Changing reproductive rates in a neotropical forest rodent, Proechimys semispinosus Journal of Animal Ecology 66: 472-480.

AMUNDALA, D., BAPEAMONI, A., IYONGO, W., KENNIS, J., GAMBALEMOKE, M., KADANGE, N., KATUALA, P.G.B. \& DUDU, A. 2005. The population structure of four rodent species from a tropical region (Kisangani, D.R. Congo). Belgian Journal of Zoology 135 (suppl.): 127-131.

AMUNDALA, D.N., KENNIS, J., LEIRS, H. \& DUDU, A.M. 2008. Farmer survey in the hinterland of Kisangani (Democratic Republic of Congo) on rodent crop damage and rodent control techniques used. Mammalia 72: 192-197.

ANDERSON, D.R., BURNHAM, K.P. \& WHITE, G.C. 1998. Comparison of Akaike information criterion and consistent Akaike information criterion for model selection and statistical inference from capture-recapture studies. Journal of Applied Statistics 25: 263-282.

BURNHAM, K.P. \& ANDERSON, D.R. 2004. Understanding AIC and BIC in model selection. Sociological Methods \& Research 33: 261-304.

BURNHAM, K.P. \& WHITE, G.C. 2002. Evaluation of some random effects of methodology applicable to bird ringing data. Journal of Applied Statistics 29: 245-264.

CHOQUET, R., LEBRETON, J.D., GIMENEZ, O., REBOULET, A-M. \& PRADEL, R. 2009. U-CARE: Utilities for performing goodness of fit tests and manipulating CApture-REcapture data. Ecography 32: 1071-1074.

DEBROUX, L., HART, T., KAIMOWITZ, D., KARSENTY, A. \& TOPA, G. 2007. Forests in post-conflict Democratic Republic of Congo: analysis of a priority agenda. A joint report by teams of the World Bank,
Center for International Forestry Research (CIFOR), Centre International de Recherche Agronomique pour le Développement (CIRAD), African Wildlife Foundation (AWF), Conseil National des ONG de Développement du Congo (CNONGD), Conservation International (CI), Groupe de Travail Forêts (GTF), Ligue Nationale des Pygmées du Congo (LINAPYCO), Netherlands Development Organisation (SNV), Réseau des Partenaires pour l'Environnement au Congo (REPEC), Wildlife Conservation Society (WCS), Woods Hole Research Center (WHRC), World Agroforestry Centre (ICRAF) and World Wide Fund for Nature (WWF). ISBN 979-24-4665-6.

DIETERLEN, F. 1986. Seasonal reproduction and population dynamics in rodents of an African lowland rain forest. Cimbebasia 8: 1-7.

DRICKAMER, L.C. 1997. Responses to ordors of dominant and subordinate house mice (Mus domesticus) in live traps and responses to odors in live traps by dominant and subordinate males. Journal of Chemical Ecology 23: 2493-2506.

DUDU, A. 1991. Etude du peuplement d'insectivores et de rongeurs de la forêt ombrophile de basse altitude de Zaire (Kisangani, Masako). Doctoral thesis, Universiteit Antwerpen, Antwerp.

DUPLANTIER, J-M. 1989. Les rongeurs myomorphes forestiers du Nord-Est du Gabon: structure du peuplement, démographie, domaines vitaux. Revue d'écologie 44: 329-346.

EGGLETON, P., BIGNELL, D.E., HAUSER, S., DIBOG, L., NORGROVE, L. \& MADONG, B. 2002. Termite diversity across an anthropogenic disturbance gradient in the humid forest zone of West Africa. Agriculture, Ecosystems \& Environment 90: 189-202.

GEMBU, T., KATUALA, G-B. \& DUDU, A. 1998. Etude du régime alimentaire de Deomys ferrugineus Thomas, 1888 (Cricetidae, Rodentia) des réserves de Faune à Okapis (RFO) et de Masako (R.D. Congo). Annales de la Faculté des Sciences UNIKIS 11: 189-199.

GIMENEZ, O., CHOQUET, R. \& LEBRETON, J-D. 2003. Parameter redundancy in multistate capture-recapture models. Biometrical Journal 45: 704-722.

GUBISTA, K.R. 1999. Small mammals of the Ituri Forest, Zaire: diversity and abundance in ecologically distinct habitats. Journal of Mammalogy 80: 252-262.

HAPPOLD, D.C.D. 1996. Mammals of the GuineaCongo rain forest. Proceedings of the Royal Society of Edinburgh, B. Biological Sciences 104: 243-284.

JULLIARD, R., LEIRS, H., STENSETH, N.C., YOCCOZ, N.G., PREVOT-JULLIARD, A.C., VERHAGEN, R. \& VERHEYEN, W. 1999. Survival-variation within and between functional categories of the African multimammate rat. Journal of Animal Ecology 68: 550-561.

KASANGAKI, A., KITYO, R. \& KERBIS-PETERHANS, J. 2003. Diversity of rodents and shrews along an elevational gradient in Bwindi Impenetrable National Park, south-western Uganda. African Journal of Ecology 41: 115-123.

KATUALA, P.G.B., HART, J.A., HUTTERER, R., LEIRS, H. \& DUDU, A. 2005. Biodiversity and ecology of small mammals (rodents and shrews) of the 'Réserve de Faune à Okapis', Democratic Republic of the Congo. Belgian Journal of Zoology 135 (suppl.): 191-196. 
KATUALA, P.G.B., KENNIS, J., NICOLAS, V., WENDELEN, W., HULSELMANS, J., VERHEYEN, E., VAN HOUTTE, N., DIERCKX, T., DUDU, A.M. \& LEIRS, H. 2008. The presence of Praomys, Lophuromys, and Deomys species (Muridae, Mammalia) in the forest blocks separated by the Congo River and its tributaries (Kisangani region, Democratic Republic of Congo). Mammalia 72: 223-228.

KENNIS, J., SLUYDTS, V., LEIRS, H. \& VAN HOOFT, W.F.P. 2008. Polyandry and polygyny in an African rodent pest species, Mastomys natalensis. Mammalia 72: $150-160$.

KINGDON, J. 1974. East African Mammals: an Atlas of Evolution in Africa. Volume II Part B (Hares and Rodents). University of Chicago Press, Chicago.

KREBS, C. 1966. Demographic changes in fluctuating populations of Microtus californicus. Ecological Monographs 36: 239-273.

LEBRETON, J.D., BURNHAM, K.P., CLOBERT, J. \& ANDERSON, D.R. 1992. Modeling survival and testing biological hypotheses using marked animals: a unified approach with case studies. Ecological Monographs 62: 67-118.

LEIRS, H. 1995. Population ecology of Mastomys natalensis (Smith, 1834). Implications for rodent control in Africa. Belgian Administration for Development Cooperation-Agricultural Edition 35: 1-268.

LEIRS, H., VERHEYEN, W. \& VERHAGEN, R. 1996. Spatial patterns in Mastomys natalensis in Tanzania (Rodentia, Muridae). Mammalia 60: 545-555.

LIMA, M., JULLIARD, R., STENSETH, N.C. \& JAKSIC, F.M. 2001. Demographic dynamics of a Neotropical small rodent (Phyllotis darwini): feedback structure, predation and climatic factors. Journal of Animal Ecology 70: 761-775.

LINK, W.A. \& BARKER, R.J. 2006. Model weights and the foundations of multimodel inference. Ecology 87: 2626-2635.

MAKUNDI, R.H., MASSAWE, A.W. \& MULUNGU, L.S. 2006. Breeding seasonality and population dynamics of three rodent species in the Magamba Forest Reserve, Western Usumbara Mountains, north-east Tanzania. African Journal of Ecology 45: 17-21.

MALCOLM, J.R. \& RAY, J.C. 2000. Influence of timber extraction routes on central African small-mammal communities, forest structure, and tree diversity. Conservation Biology 14: 1623-1638.

MUKINZI, I., KATUALA, P.G.B., KENNIS, J., GAMBALEMOKE, M., KADANGE, N., DUDU, A., COLYN, M. \& HUTTERER, R. 2005. Preliminary data on the biodiversity of rodents and insectivores (Mammalia) in the periphery of Kisangani (D.R. Congo). Belgian Journal of Zoology 135 (suppl.): 133140.

MUSSER, G.G. \& CARLETON, M.D. 2005. Superfamily
Muroidea. In: Mammal Species of the World: A Taxonomic and Geographic Reference, (eds) D.E. Wilson \& D.M. Reeder, pp. 894-1531. Johns Hopkins University Press, Baltimore, MD.

O'BRIEN, C.J. 2009. Terrestrial small mammals from the Gamba Complex in Gabon: distribution patterns and landscape influences. Online at: http://digitalcommons.usu.edu/etd/353 (All graduate theses and dissertations. Paper 353). Utah State University, Utah.

OTIS, D.L., BURNHAM, K.P., WHITE, G.C. \& ANDERSON, D.R. 1978. Statistical inference from capture data on closed animal populations. Wildlife Monographs 62: 1-135.

POCOCK, M.J.O., FRANTZ, S.C., COWAN, D., WHITE, P. \& SEARLE, J. 2004. Tapering bias inherent in minimum number alive (MNA) population indices. Journal of Mammalogy 85: 959-962.

PRADEL, R., GIMENEZ, O. \& LEBRETON, J.D. 2005. Principles and interest of GOF tests for multistate capture-recapture models. Animal Biodiversity and Conservation 28: 189-204.

RAHM, U. 1970. Note sur la reproduction des Sciuridés et Muridés dans la forêt équatoriale au Congo. Revue suisse de Zoologie 77: 635-646.

SWIHART, R.K., GEHRING, T.M., KOLOZSVARY, M.B. \& NUPP, T.E. 2003. Responses of 'resistant' vertebrates to habitat loss and fragmentation: the importance of niche breadth and range boundaries. Diversity and Distributions 9: 1-18.

THOEN, D. \& BA, A.M. 1989. Ectomycorrhizas and putative ectomycorrhizal fungi of Afzelia africana Sm. and Uapaca guineensis Müll. Arg. in southern Senegal. New Phytologist 113: 549-559.

WATT, A.D., STORK, N.E. \& HUNTER, M.D. (1997) Forests and Insects. Chapman \& Hall, London.

WELLS, K., KALKO, E.K.V., LAKIM, M.B. \& PFEIFFER, M. 2008. Movement and ranging patterns of a tropical rat (Leopoldamys sabanus) in logged and unlogged rain forests. Journal of Mammology 89: 712-720.

WELLS, K., PFEIFFER, M., LAKIM, M.B. \& LINSENMAIR, K.E. 2004. Use of arboreal and terrestrial space by a small mammal community in a tropical rain forest in Borneo, Malaysia. Journal of Biogeography 31: 641-652.

WHITE, G.C. \& BURNHAM, K.P. 1999. Program MARK: survival estimation from populations of marked animals. Bird Study 46 (suppl.): 120-138.

WILKIE, D.S. 1990. Slash-burn cultivation and mammal abundance in the Ituri Forest, Zaïre. Biotropica 22: 90-99.

WOLFF, J.O. 2007. Social biology of rodents. Integrative Zoology: 193-204.

YUNGER, J.A. 2004. Movement and spatial organization of small mammals following vertebrate predator exclusion. Behavioural Ecology 139: 647-654.

Responsible Editor: A. Monadjem 